\title{
POST APPENDICECTOMY RIGHT ILIAC FOSSA PAIN A PROSPECTIVE STUDY
}

\author{
AAMR A. YOUSIF, MBCHB, CABS* \\ ABDULGHAFOOR S. ABDULKAREEM, MBCHB, FICMS** \\ SAAD F. ELIAS, MBCHB, CABS***
}

\section{Submitted 17 June 2019; accepted 22 November 2019}

\begin{abstract}
Background: Diagnosis of acute appendicitis continues to be a real challenge in clinical setting. The recurrence or persistence of pain in the right lower abdomen following appendicectomy is known as post appendicectomy syndrome. This is mainly duetopreoperative misdiagnosis (or over diagnosis) and/or postoperative complications. Negative appendicectomy (appendicectomy in the absence of appendiceal disease) rate has been on the rise. In this study, we looked at patients with recurrent orpersistent right iliac fossa pain post-appendicectomy and investigated the potential causes for this.

Patients and methods: A prospective study, 47 post-appendicectomy patients presented to Duhok Emergency Hospital, Kurdistan region, Iraq with recurrent or persistent right iliac fossa pain (January 2017 - January 2019). Detailed history taking and clinical examination, as well as appropriate investigations were undertaken as well as review of the previous admission records, investigations, surgical notes and histopathology reports.

Results: Clinical assessment and investigations confirmed the presence of primary cause, other than acute appendicitis or appendectomy-related, for the pain (negative appendicectomy). These included: gastroenterological and inflammatory (lymphadenitis, adhesions, stump appendicitis, familial Mediterranean fever, and perforated duodenal ulcer), gynaecological (ovarian cyst, dysmenorrhea, polycystic ovary syndrome), urological (renal stones, ureteric stone, acute right pyelonephritis) and locomotors (disc prolapsed). In 22 patients, no surgical cause was found and a diagnosis of functional pain was given.

Conclusion: In our study, we have managed to identify the causes of negative appendicectomy. We could not quantify the incidence of such cases but do recognise that these cases raise a question about how to improve diagnostic accuracy. Until now, no diagnostic tool could give a $100 \%$ accurate diagnosis but rather a combination of clinical judgement following history and appropriate examination and investigations.
\end{abstract}

Duhok Med J 2020; 14 (1): 1-11.

Keywords: Appendicitis; Appendicectomy; Negative appendicectomy; RIF pain.

ppendicitis is the acute inflammation
of the appendix. It is commonly caused by an infection secondary to obstruction of the lumen of the appendix (usually due to a faecolith). By far it is one of the leading causes for abdominal pain in young adults and children, and accounts for a large amount of hospital admissions every year ${ }^{1}$. Documented risk factors include male gender, age (10-20 years), smoking (active, or passive in children) and frequent antibiotic use (e.g. imbalance of gut flora can trigger appendicitis). The diagnosis is mainly based on history and clinical examination, with classic presentation (migrating peri-umbilical pain to the right iliac fossa, with guarding or rebound tenderness, anorexia and nausea)

\footnotetext{
* Lecturer, College of Pharmacy, University of Duhok, Kurdistan Region, Iraq.

** As sis tant Prof, Department of the Surgery, College of Medicine, University of Duhok, Kurdistan Region, Iraq

*** General Surgeon, Emergency Hospital of Duhok,Kurdistan Region, Iraq
}

Correspondence author: Aamr A. Yousif, aamr.avub@uod.ac, Mobil +7701718618 
present in $50 \%$ of the patients with confirmed diagnosis of the condition ${ }^{2}$.

Further investigations are necessary to rule out other causes including gastrointestinal, urological and gynaecological conditions as well as shingles and diabetic ketoacidosis. Routine investigations usually include: haematological and biochemical (i.e. complete blood count $[\mathrm{CBC}]$ and $\mathrm{C}$-reactive protein [CRP]), urine analysis (abnormal in $50 \%$ of acute appendicitis patients), pregnancy test (when indicated), ultrasound or computed tomography investigation of the abdomen and pelvis or exploration laparoscopy ${ }^{3}$.

Diagnostics challenges have been identified in up to $50 \%$ of acute appendicitis cases due to atypical presentations, which is mainly seen in infants and young children (only vague abdominal pain), elderly (lack of pain and fever) as well as pregnant patients. The anatomical position of the appendix is also a factor that can influence and lead to atypical presentation with retrocaecal/ retrocolic appendix presenting with right loin pain, while a subcaecal and pelvic appendix can present with suprapubic pain and urinary frequency. Hence it is not uncommon for patients with abdominal pains, especially in the right iliac fossa, to be diagnosed with acute appendicitis and undergo surgery and then return with recurrent or persistent pain, which may suggest a non-appendicealcause ${ }^{4}$.

Acute appendicitis is a medical emergency, which requires hospital admission. Appropriate and timely management has been linked to good prognosis. If not managed appropriately, complications may arise including perforation (most common), which begin after 12 hours of progressive localised inflammation, peritonitis and sepsis. Depending on the clinical assessment and investigations, the surgeon may choose a conservative approach with intravenous antibiotics with watchful waiting with/out elective laparoscopic surgery or proceed to open emergency surgery ${ }^{1-3}$.

The surgical procedure has been linked to a number of short-term and long-term complications, with complications being higher in the open surgical approach. Open surgical approach is mainly undertaken for emergency rather than routine elective cases. Most common complications include ileus (median prevalence $1.1 \%$ ), incisional hernia (median prevalence $0.7 \%$ ), inflammatory bowel disease (median prevalence for ulcerative colitis $0.1 \%$, and Crohn's disease $0.2 \%$ ) with studies reporting links to colorectal cancer and infertility. Mortality has been reported in both laparoscopic approach (median $0.9 \%$, range $0.3 \%-3.6 \%$ ) and open surgical approach (median 1.8\%, range $0.6-8.6 \%)^{1,2,4}$.

Persistent right iliac fossa pain postappendicectomy has been reported and is not that uncommon. Nowadays this is being looked at as a cause that is not related to the surgical procedure but rather a primary one (non-appendiceal disease) and requires further investigations. It is vital to be aware of these causes before rushing into an acute appendicitis diagnosis, which could save the patient unnecessary surgery and its related short and long-term complications ${ }^{5}$.

In this study, we looked at patients with recurrent or persistent right iliac fossa pain post-appendicetomy and investigated the potential causes for this. 


\section{PATIENTS AND METHODS}

In this prospective study, 47 postappendicectomy patients presented to Duhok Emergency Hospital, Kurdistan region, Iraq with recurrent or persistent pain (January 2017 - January 2019). Prior to conducting the study, a proposal was submitted to the appropriate university committee and approval was granted. The patients' data were entered onto proformas. The fields included a range of clinical and operative variables related to recurrent/persistent abdominal pains. All patients verbal consented to be included in this study.

The patients were assessed bearing in mind possible causes for such pain which could be directly related to the surgery or the fact it may represent a primary pain (i.e. another diagnosis). Detailed history taking and clinical examination was undertaken as well as review of the previous admission records, investigations, surgical notes and histopathology reports.

A full set of haematological and biochemical investigations were implemented for all patients, including CBC, urea \& electrolytes [U\&Es - renal function test], liver function test (LFT) and CRP. Urine analysis with further investigations, including pregnancy testing, ultrasonography (US) and/or computed tomography (CT) of the abdomen, intravenous urogram (IVU) and even exploration laparoscopywere undertaken, when indicated.

If the working diagnosis fell outside the expertise of the authors (i.e. general surgery/urology), the patients were referred to other relevant disciplines (i.e. gastroenterology, gynaecology or other acute medical services) for further assessment and treatment. Patients were then followed-up by the appropriate disciplines and managed until the pain symptoms subsided.

\section{RESULTS}

The patients' population comprised 9 (20\%) males and $38(80 \%)$ females (M:F ratio1:4.2). Their mean age at presentation was 22.5 years (range 4-79). Duration at presentation was variable from immediate postoperative period up to one year post appendicectomy. More than half of the patients presented after six months from time of surgery. None of the female patients included in this study were pregnant.

Clinical assessment and investigations confirmed the presence of another primary cause, other than acute appendicitis or appendicectomy-related, for the pain (Figure 1). These included:

Gastroenterological and inflammatory: $(21 \%)$

- Lymphadenitis: 4 patients

- Adhesions: 3 patients

- Stump appendicitis: 1 patient

- Familial Mediterranean fever (FMF auto-inflammatory): 1 patient

- Perforated duodenal ulcer: 1 patient Gynaecological: (17\%)

- Ovarian cyst: 3 patients

- Dysmenorrhea: 4 patients

- Polycystic ovary syndrome (PCOS): 1 patient

Urological: (12.8\%)

- Renal stones: 3 patients

- Ureteric stone: 2 patients

- Acute right pyelonephritis: 1 patient

Locomotor: $(2.1 \%)$

- $\quad$ Disc prolapse: 1 patient 
Functional - no clear surgical cause was found in the rest $22(47 \%)$ patients, with likely causes including:
Psychological

Irritable bowel syndrome

Muscular

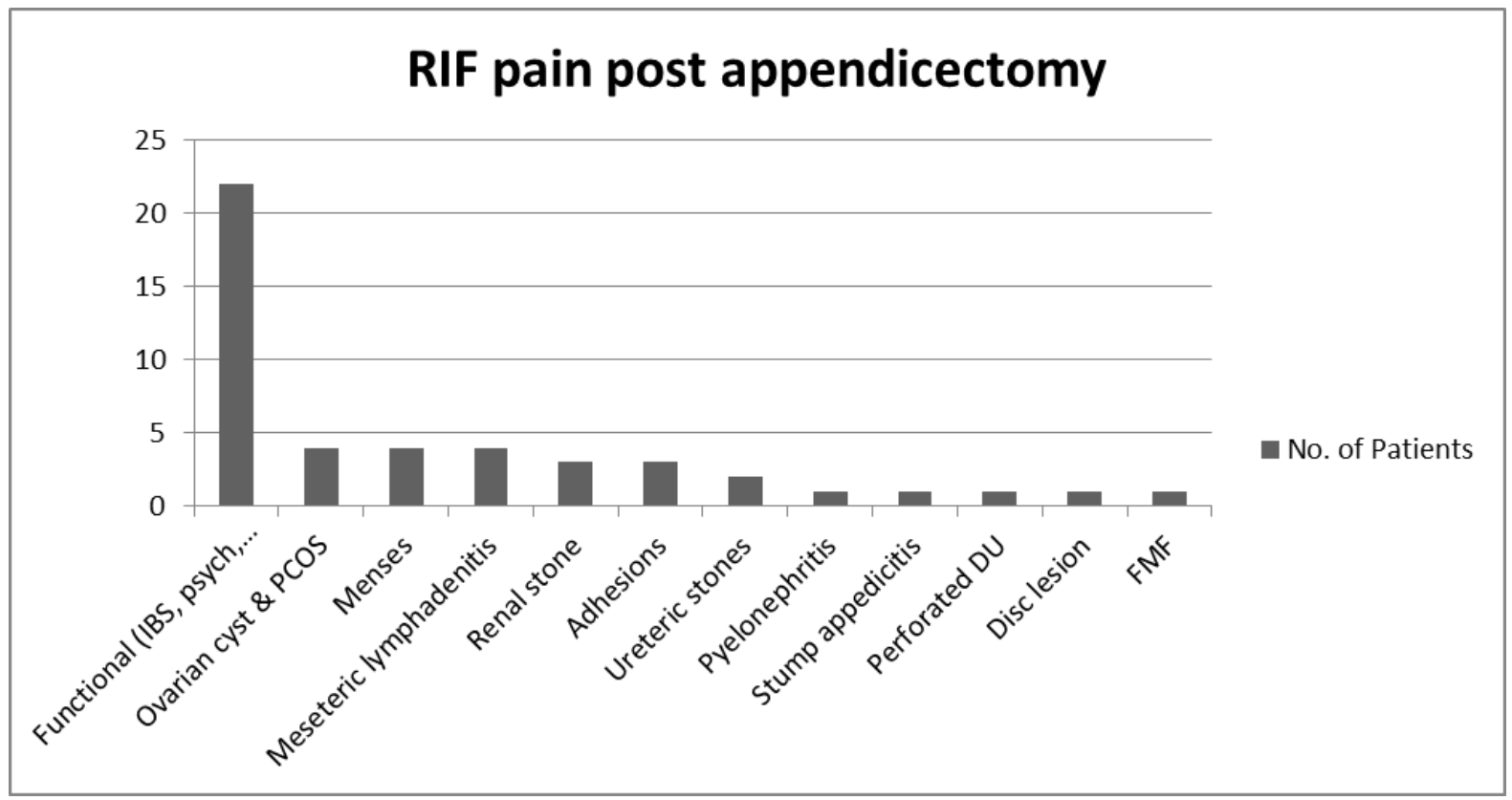

Figure 1: The distribution of 47 patients with post appendicectomy syndrome

Four patients were subjected to laparoscopic evaluation for their pain (adhesions were found in 3 and bleeding ovarian cyst was found in one patient).

In our study the male patients were more prone to organic pathology, such as stump appendicitis, perforated duodenal ulcer and FMF, while the female patients were more prone to functional pain of menses and irritable bowel syndrome). No clear surgical cause was found in the $22(47 \%)$ of the patients, with likely diagnoses of irritable bowel syndrome, muscular or psychological causes were attributed.

All patients who needed second surgical intervention were managed electively; andnone of them required emergency surgery.

\section{DISCUSSION}

Management of suspected acute appendicitis continues to be via open surgical approach. Diagnosis of acute appendicitis continues to be a real challenge in clinical setting, with about half of the patients with true appendicitis presenting with atypical fashion while at least a third is over diagnosed and end up having unnecessary surgical intervention with the added risks of short-term and long-term complications ${ }^{1-4}$.

The recurrence or persistence of pain in the right lower abdomen following appendicectomy is known as post appendicectomy syndrome (PAS). The condition arises from two possibilities: preoperative misdiagnosis (or over diagnosis) and/or postoperative complications. Table 1 illustrates possible differential diagnosis for conditions that may mimic acute appendicitis. The gold standard approach remains history taking and clinical examination, aided with diagnostic tests based on clinical judgement. In a study, Hardin 


\begin{tabular}{|c|c|}
\hline Duhok Medical Journal & Volume 14, Issue 1,2020 \\
\hline $\begin{array}{l}\text { recommended rectal examin } \\
\text { an assessment for a suspected } \\
\text { as it can provide useful infor } \\
\text { when the diagnosis is uncl } \\
\text { recommended blood test } \\
\text { urinalysis as part of the } \\
\text { process, and to use US }\end{array}$ & $\begin{array}{l}\text { during challenging cases. Ultimately, the article } \\
\text { dicitis, reached a conclusion that delay in } \\
\text { a, only diagnosing appendicitis increases the risk } \\
\text { Hardin of perforation and complications, hence a } \\
\text { and balance should be achieved between "time } \\
\text { igation } \\
\text { CT in }\end{array}$ \\
\hline Table 1: Cond & that are mis diagnosed as acute appendicitis \\
\hline Discipline & Related conditions \\
\hline Congenital conditions & $\begin{array}{l}\text { Missed Meckel's diverticula } \\
\text { Congenital renal malformations }\end{array}$ \\
\hline $\begin{array}{l}\text { Inflammatory conditions and } \\
\text { other bowel-related conditions }\end{array}$ & $\begin{array}{l}\text { Gastroenteritis } \\
\text { Intussusception } \\
\text { Non-specific mesenteric lymphadenitis } \\
\text { Crohn's ileitis } \\
\text { Acute cholecystitis } \\
\text { Diverticulitis (Meckel's and colonic) } \\
\text { Terminal ileitis } \\
\text { Ileocecal tuberculosis } \\
\text { Worm (enterobiasis) } \\
\text { Amoebic typhlitis } \\
\text { Familial Mediterranean fever (autoinflammatory) } \\
\text { Stump appendicitis } \\
\text { Irritable bowel syndrome }\end{array}$ \\
\hline Urological & $\begin{array}{l}\text { Chronic UTIs } \\
\text { Right ureteric stone } \\
\text { Tubercular cystitis } \\
\text { Right pyelonephritis } \\
\text { Non-specific haematuria }\end{array}$ \\
\hline Gynaecological & $\begin{array}{l}\text { Ectopic pregnancy } \\
\text { Right salpingooophoritis } \\
\text { Small right ovarian cyst } \\
\text { Ovarian torsion } \\
\text { Ruptured ovarian follicle } \\
\text { Pelvic inflammatory disease } \\
\text { Dysmenorrhea } \\
\text { PCOS }\end{array}$ \\
\hline Neurological & $\begin{array}{l}\text { Prolapsed intervertebral disc producing radiating } \\
\text { spinal pain }\end{array}$ \\
\hline Psychosomatic & $\begin{array}{l}\text { Appendix phobia } \\
\text { Hysterical pain }\end{array}$ \\
\hline Others & $\begin{array}{l}\text { Rectus sheath haematoma } \\
\text { Porphyria } \\
\text { Diabetic ketoacidosis } \\
\text { Shingles }\end{array}$ \\
\hline
\end{tabular}

In a study by Das et al., 912 clinical suspicion of acute appendicitis appendicectomies were performed on during the period of 6 years. The negative 
appendicectomy (appendicectomy in the absence of appendiceal disease) rate in this study was $36.40 \%$. Furthermore, females had a higher number of negative appendicectomy at $40.34 \%$. The study came to conclude that surgeons tend to over diagnose fearing to miss an acute appendicitis, which is linked with high morbidity and mortality. Furthermore, the researchers recommended a thorough work-up with preoperative imaging and diagnostic laparoscopy, where applicable, to enhance diagnosis and prevent over diagnosis ${ }^{1}$.

When it comes to gender, out of 47 patients included in this study, 38 patients were females. Similarly most of the studies concluded that female patients are more (75-100\%) prone to right iliac fossa pain due to gynecological disorders such as pelvic inflammatory disease and endometriosis and high percent of negative appendicectomy with high morbidity $5,7,8,9,10,11$.

To reduce the rate of negative appendicectomy, more publications are now recommending the use of noncontrast CT to investigate suspected appendicitis. Malone and Shetty reported that unenhanced CT scanning has a high level of accuracy in diagnosing acute appendicitis. Furthermore, many unsuspected diseases have been discovered during the course of the unenhanced CT examination $^{3}$. Many studies that followed confirmed that CT was accurate and reliable as a diagnostic tool for acute appendicitis, but a number of controversies arose which was mainly related to risk of radiation and that many surgeons feared that the attempt to reduce over diagnosing appendicitis (negative appendicectomy rate) may eventually lead to increase in frequency of perforated cases ${ }^{4}$.

In a study by Walker et al, patients were randomised to receive mandatory $\mathrm{CT}$ scanning or not for suspected appendicitis. The negative appendicitis rate was reduced by mandatory CT scan and the clinical management was changed in $26 \%$ of the patients, meaning that a quarter of the patients in the study that presented with suspected appendicitiswerefound to not have appendiceal disease and did not undergo surgery ${ }^{12}$. While another study did not find mandatory $\mathrm{CT}$ to be superior to clinical examination in reducing the rate of negative appendicitis ${ }^{13}$. On the whole, authorities around the world seem to agree that CT scanning is the tool of choice that can help to provide a relatively precise diagnosis in challenging cases.

The use of ultrasonography in diagnosing acute appendicitis has some advantages (mainly no radiation) but on the whole was found to be inferior in diagnostic accuracy when compared to $\mathrm{CT}^{14}$. When compared to magnetic resonance imaging (MRI), Cobben et al., and in a group of 36 patients, reported that MRI was able to diagnose acute appendicitis in 8 patients and identified 4 patients with alternative diagnoses, while US reported no abnormalities in any of those 12 patients. The authors of the study recommended MRI as a tool that can reduce negative appendicectomy rate, and save those patients unnecessary operations ${ }^{15}$.

The introduction of scoring system was a new way to try and reduce the rate of over diagnosis/ negative appendicectomy. Several scores have been introduced with the most well recognised one being the Alvarado score ${ }^{16}$. The score was 
introduced as a practical score for early diagnosis of acute appendicitis and was mainly based on 3 signs (RLQ tenderness, rebound pain and increased temperature of $\geq 37.3{ }^{\circ} \mathrm{C}$ ), 3 symptoms (migration of abdominal pain to the RLQ, anorexia and nausea/vomiting) and 2 laboratory findings (leukocytosis and neutrophilia). A recent study applied the score on 766 adult and paediatric patients and found it to be $75 \%$ accurate, with $83 \%$ sensitivity and $86.7 \%$ positive predictive value ${ }^{17}$.

Laparoscopy is a safe and effective diagnostic and therapeutic tool in patients with uncertain cause for chronic abdominal pain. Ondersand Mittendorf, Ellabban et al. and Szomstein et al. found that adhesions are the main laparoscopic findings in more than $60 \%$ of their patients with past abdominal surgery including appendicectomy, and $80-90 \%$ of them will have their pain relieved after laparoscopic adhesiolysis $9,18,19$. On a separate note, diagnostic laparoscopy has been looked at as beneficial tool in acute appendicitis. In a meta-analysis, which included 14 studies, the reduction in negative appendicectomyratehas been impressive (RR 0.37; CI 0.13 to 1.01), especially among reproductive-age women (RR 0.20; CI 0.11 to 0.34$)^{20}$.

Studies from the reviewed literature on clinical skills and laboratory investigations for suspected appendicitis seems to agree that patients should received per rectal examination when diagnosis could not be confirmed, and that blood testing for inflammatory markers should be offered routinely to every patient. Furthermore, the diagnostic aids for acute appendicitis suggests that computed tomography, magnetic resonance imaging and/or diagnostic or exploration laparoscopy should always be offered when dealing with challenging cases, if not part of the routine investigations.

Our study included patients with uncommon negative appendicectomy diagnosis including stump appendicitis and familial Mediterranean fever. Stump appendicitis is an inflammation of remnant appendix tissue due to incomplete surgical removal of the appendix, (if more than 5 mm stump left) usually due to technical or local anatomical factors. Its clinical presentation is similar to the classical appendicitis and its diagnosis is usually delayed because of past history of appendicectomy and that is why mostly present with complications ${ }^{21}$. In our patient with stump appendicitis, the patient operated for local abscess three days after presentation.

While, familial Mediterranean fever is a rareauto inflammatory disease, Karaaslanetal. And Majeed et al found that abdominal pain or peritonitis was present in $85-92 \%$ of their patients with FMF and one third of them were subjected to unnecessary abdominal surgery, reflecting the diagnostic difficulties. More than $40 \%$ of patients with FMF had history of surgery and its diagnosis is often missed and markedly delayed for more than 20 years as more than $50 \%$ of them have negative family history of $\mathrm{FMF}^{22,23}$. Kisacik et al. established the diagnosis of FMF in $7.7 \%$ of his patients with negative appendicectomy ${ }^{24}$.

\section{CONCLUSION}

In our study, we have managed to identify cases that were over diagnosed or 
misdiagnosed as acute appendicitis where the patients ended-up undergoing unnecessary open appendicectomy in the absence of appendiceal disease. We could not quantify the incidence of such cases but do recognise that this number raises a question about how to improve diagnostic accuracy. Until now, no diagnostic tool could give a $100 \%$ accurate diagnosis but rather a combination of clinical judgement following history and appropriate examination and investigations.

\section{CONFLICT OF INTEREST}

We declare none

\section{REFERENCES}

1. Das MK, Gautam D, Roy H, Mukherjee A, Gaurav R, Sen S. Unnecessary appendicectomy in suspected cases of acute appendicitis. J Indian Med Assoc. 2009 Jun;107(6):354, 356-7.

2. Flum DR, Morris A, Koepsell T, Dellinger EP. Has misdiagnosis of appendicitis decreased over time? A population-based analysis. JAMA. 2001; 286(14):1748-53.

3. Malone AJ, Shetty MR. Diagnosis of appendicitis. Lancet. 1997 Jun 14;349(9067):1774.

4. AanningHL.Negative appendectomy and perforation rates in the SCOAP trial. Ann Surg. 2009; 249(4):699.

5. Chakraborty T, Pan S. The menace of persisting right iliac fossa pain after appendectomy - are we over doing it?JEMDS. 2017 Mar; 21 (6):173135.
6. Hardin DM Jr. Acute appendicitis: review and update. AmFam Physician. 1999 Nov 1;60(7):2027-34.

7. Lamture Y, Gajbhiye V, Shinde R, Kher K. Impact of post appendectomy pain. International Surg J.2017 Sep;4(9):2932-2936

8. Vaishnav U, Patel HS. Analysis of diagnostic laparoscopy in chronic right iliac fossa pain.IntSurg J. 2017; 4(4):1259-62.

9. Onders RP, Mittendorf EA. Utility of laparoscopy in chronic abdominal pain. Surgery. 2003;134:552-4.

10. Mock K, Lu Y, Friedlander S, Kim DY, Lee SL. Misdiagnosing adult appendicitis: clinical, cost, and socioeconomic implications of negative appendectomy. Amer J Surg. 2016; 212(6):1076-82.

11. Killen MC, Habeeb AH. Right iliac fossa pain in females under thirty: the role of ultrasound scanning.IJS 2012; 10(8) 29.

12. Walker S, Haun W, Clark J, McMillin K, Zeren F, Gilliland T. S, Haun W, Clark J, et al. The value of limited computed tomography with rectal contrast in the diagnosis of acute appendicitis. Am J Surg. 2000; 180(6):450-4.

13. Hong JJ, Cohn SM, Ekeh AP, Newman M, Salama M, Leblang SD.. A prospective randomized study of clinical assessment versus computed tomography. Surg Infect (Larchmt).2003; 4(3):231-9.

14. Poortman, Oostvogel HJ M, Bosma E, Lohle PNM, Cuesta MA, de Lange-de Klerk ESM, Hamming JF.. Improving diagnosis of acute appendicitis: results of a diagnostic pathway 1with 
standard use of ultrasonography followed by selective use of CT. J Am Coll Surg. 2009; 208(3):434-41.

15. Cobben L, Groot I, KingmaL, Coerkamp E, Puylaert, Blickman JJ.. A simple MRI protocol in patients with clinically suspected appendicitis: results in 138 patients and effect on outcome of appendectomy. EurRadiol. 2009; 19(5):1175-83.

16. Alvarado A. A practical score for the early diagnosis of acute appendicitis. Ann Emerg Med. 1986; 15(5):557-64.

17. Lee SL, Walsh AJ, Ho HS. Computed tomography and ultrasonography do not improve and may delay the diagnosis and treatment of acute appendicitis. Arch Surg. 2001; 136(5):556-62.

18. El-labban GM, Hokkam EN. The efficacy of laparoscopy in the diagnosis and management of chronic abdominal pain. J Minim Access Surg. 2010 Oct-Dec; 6(4): 95-99.

19. Szomstein S, Lo Menzo E, Simpfendorfer C, Zundel N, Rosenthal RJ. Laparoscopic lysis of adhesions. World J Surg. 2006 Apr;30(4):535-40.

20. Sauerland S, Jaschinski T, Neugebauer EA. Laparoscopic versus open surgery for suspected appendicitis. Cochrane Database Syst Rev. 2010; (10):CD001546.
21. Durgun AV, Baca B, Ersoy Y, Kapan M. Stump appendicitis and generalized peritonitis due to incomplete Appendectomy. Tech Coloproctol. 2003;(7):102-104

22. Karaaslan Y, Dogan I, Omma A, Sandikci SC. How long is the diagnosis of Familial Mediterranean Fever (FMF) delayed in a region where FMF is common in Turkey? PedRhe. 2015; 13(Suppl 1):P82.

23. Majeed HA, Barakat M. Familial mediterranean fever (recurrent hereditary polyserositis) in children: analysis of 88 cases. Euro J Ped. 1989; 148(7): 636-41.

24. Kisacik B, Karabicak I, Erol MF, Ozer S, Pehlivan Y, Onat AM, et, al. Is familial Mediterranean fever (FMF) common in patients with negative appendectomy? Mod Rhe. 2013; 23 (2):330-33. 


\section{يوخته

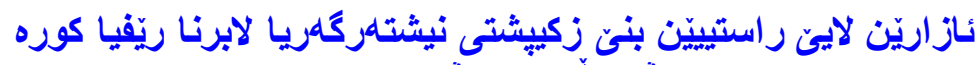

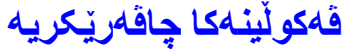

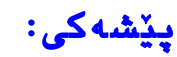

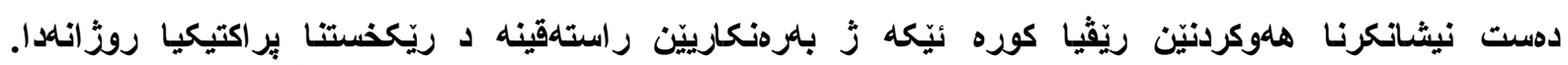

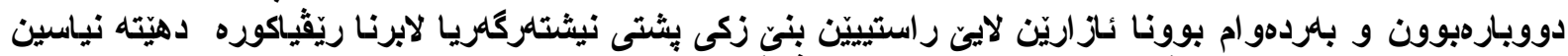

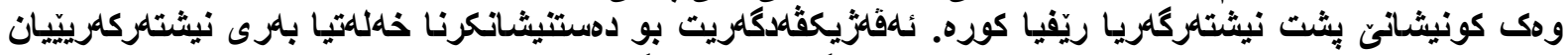

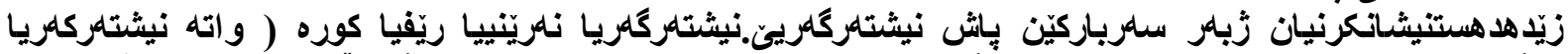

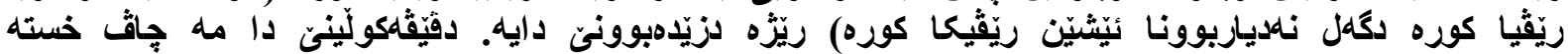

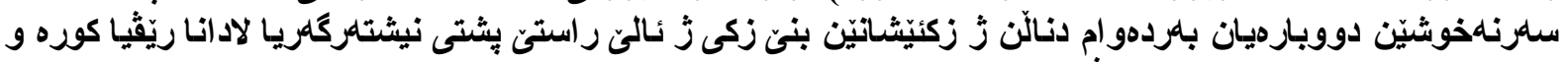

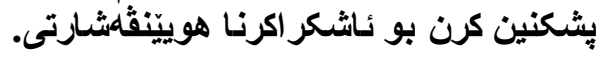

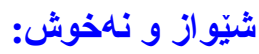

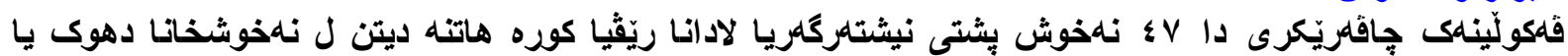

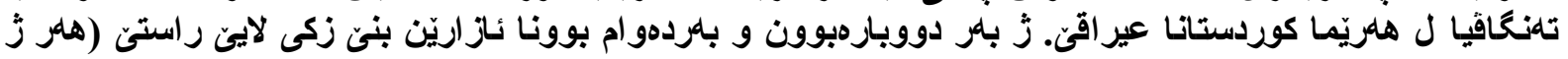

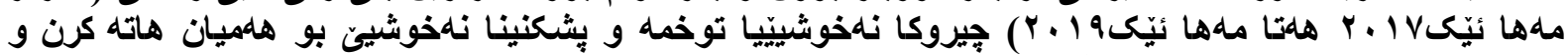

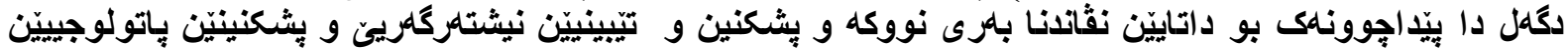
بكرنوكه هاتمكرن

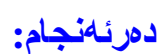

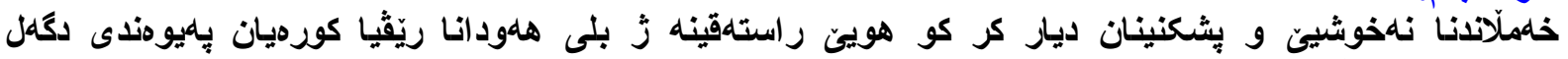

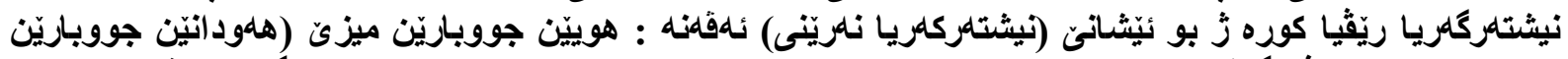

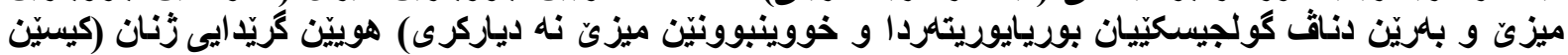

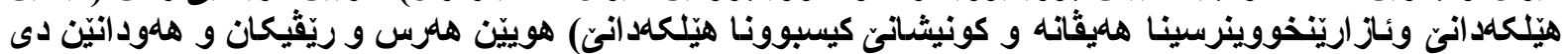

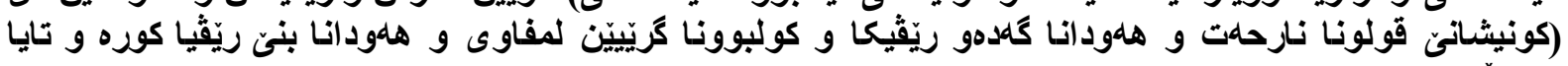

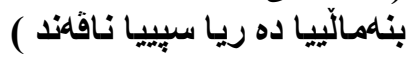

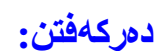

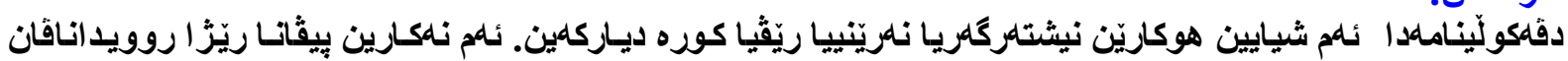

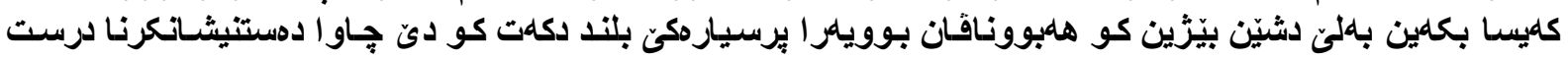

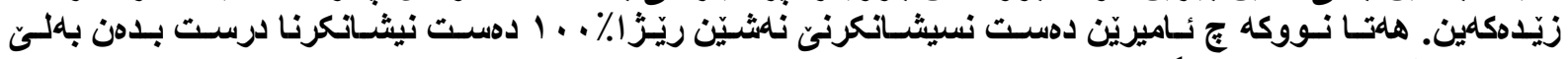

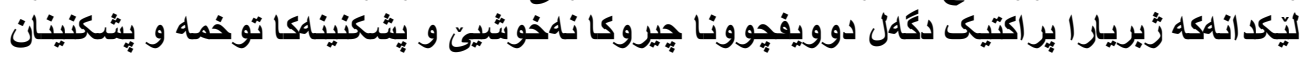




\section{الخلاصة}

\section{الام الحفرة الحرقفية اليمنى مابعد استئصال الزائدة الدودية \\ دراسة مستقبلية}

خلفية البحث أته

تشخيص التهاب الزائدة الدودية الحاد لا يزال يشكل تحديا حقيقيا في الإعدادات السريرية. يُعرف تكرار الألم أو استمراره

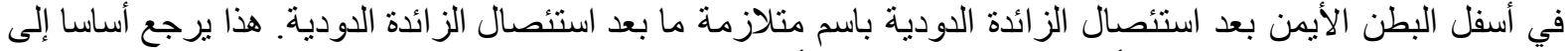

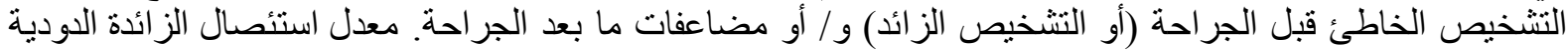

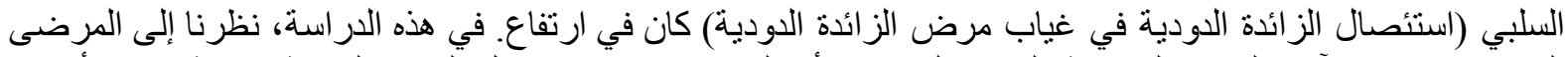

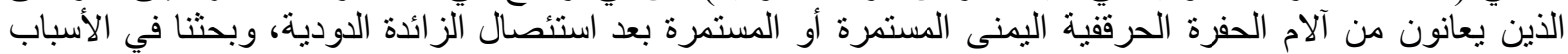
المحتملة لذلك.

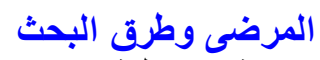

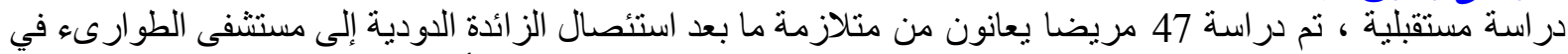

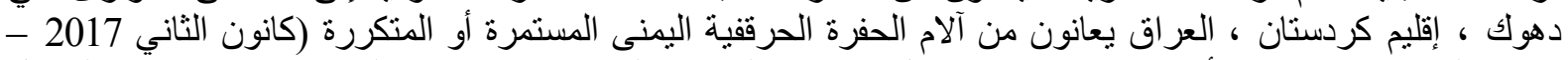

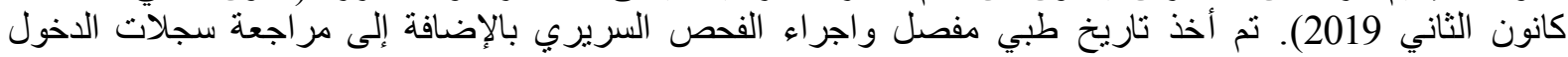
و الفحوص الطبية|لسابقة والملاحظات الجراحية وتقارير الفحص المرض النسيجي.

أكد التقييم السريري والتحقيقات وجود سبب أولي، بخلاف التهاب الزائدة الدودية الحاد للألم (استئصال الزائدة الدودية

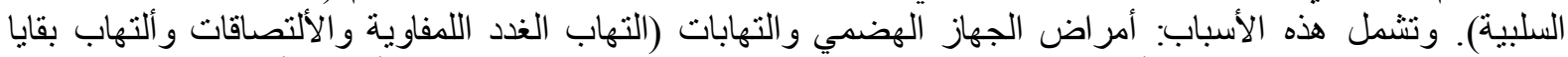

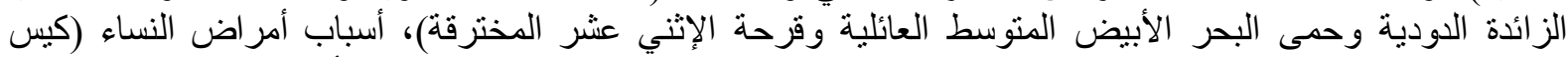

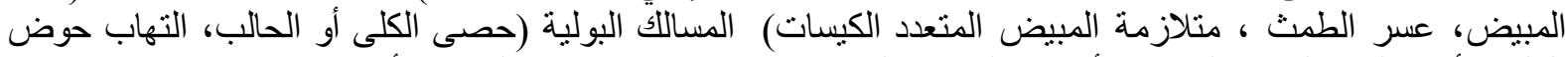

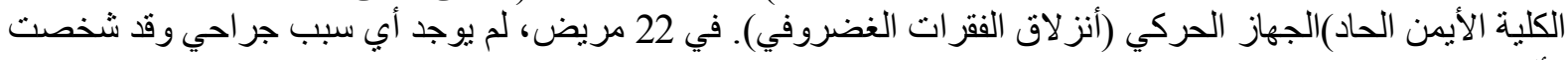
كألم وظيفي.

الاستنتاجات

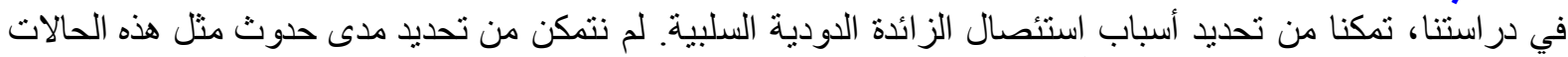

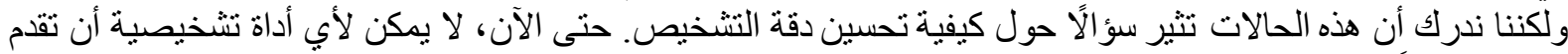

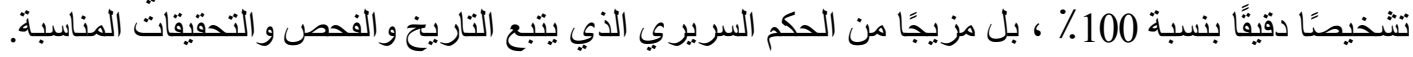

